\title{
Swelling and shrinkage of gas shales due to suction variations
}

\author{
Jinwoo Kim ${ }^{1}$, Alessio Ferrari ${ }^{1}$, Russell Ewy ${ }^{2}$, and Lyesse Laloui ${ }^{1}$ \\ ${ }^{1}$ Swiss Federal Institute of Technology Lausanne (EPFL), Laboratory of Soil Mechanics, EPFL ENAC IIC LMS, Station \\ 18, CH-1015 Lausanne, Switzerland \\ ${ }^{2}$ Independent Researcher
}

\section{Introduction}

Gas shales are saturated with multi-phase pore fluids: brine and liquid and/or gas hydrocarbons. The water (brine) saturation is usually low in native states but is easily altered by direct contact with fluids (e.g., hydraulic stimulation) or exposure to air. In such situations gas shales will swell or shrink - with important consequences in natural gas production from unconventional shale reservoirs as well as sample handling in the laboratory (Ewy, 2015). Previous studies have highlighted implications of these phenomena, including the excess water uptake upon swelling (Minardi et al., 2018) and the elastic and strength properties evolution (Ferrari et al., 2018). However, the rheological basis of gas shales under the effect of suction is still poorly understood. This study is focused on examining the volumetric deformation of gas shales as a function of imposed suction and water saturation. The swelling and shrinkage of an organic-rich shale in the absence of mechanical confining stress are characterized by controlled suction experiments (Kim et al., 2021). The observed water retention behavior and its coupling with volumetric deformation is presented and discussed. We anticipate our results to be a starting point for a rigorous theoretical stress-strain framework, with an appropriate definition of effective stress for gas shales in partially saturated conditions.

\section{Controlled suction experiments}

An experimental setup was built to quantify the volumetric deformation in gas shales at various water saturation states as shown in Figure 1. Several samples of an organic-rich shale from an unconventional play in North America were prepared in a cylindrical shape with the bedding plane being horizontal and placed on a plastic rack in a sealed glass jar. Different water saturation states were obtained by imposing suction values to the samples by the vapor equilibrium technique (Romero, 2001); a saturated saline solution with a known relative humidity $(\mathrm{RH})$ or deionized (DI) water was placed at the bottom of the jar so that water exchange between the sample and the solution can occur through the vapor phase. The total suction of the sample is related to the RH in the pore air phase by the psychrometric law (Fredlund \& Rahardjo, 1993):

$$
\psi=-\frac{R T \rho_{w}}{m_{w}} \ln (R H)
$$

where $\psi$ is the total suction, $\mathrm{R}$ is the ideal gas constant, $\mathrm{T}$ is absolute temperature, $\rho_{\mathrm{w}}$ is the density of water, $\mathrm{m}_{\mathrm{w}}$ is the molar mass of water, and RH is the relative humidity.

An experimental program was designed to simulate water saturation changes associated with hydraulic fracturing, or exposure to water/brine or high humidity in the laboratory, and subsequent water imbibition into the shale matrix. This includes a series of suction steps, either wetting or drying of the shale samples without confining stress applied. Table 1 lists the saturated saline solutions used in the experiments and their $\mathrm{RH}$ and total suction values at a reference temperature of $25{ }^{\circ} \mathrm{C}$. As schematically shown in Figure 1, a suction step includes regular bulk mass $\left(\mathrm{M}_{\mathrm{b}}\right)$ measurements every 2-3 days during equilibrium and caliper measurements at the end

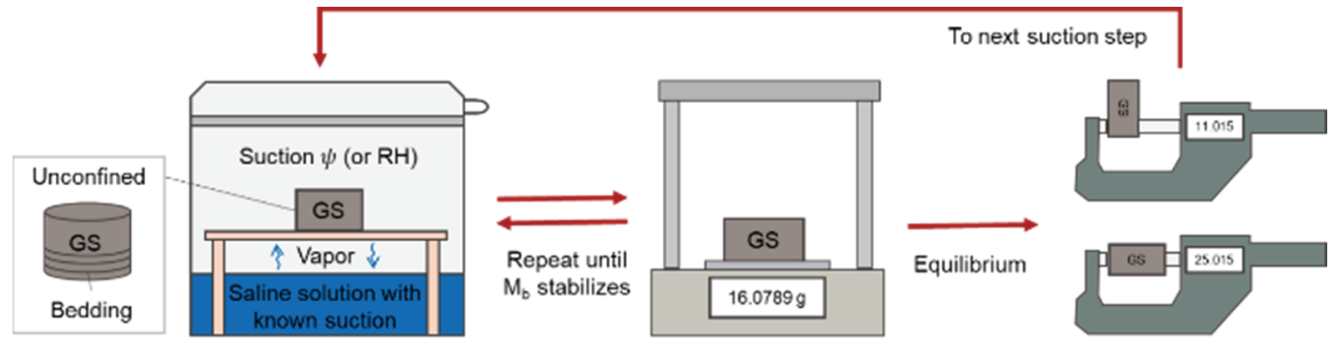

Fig. 1: Schematic showing the experimental setup and the general experimental procedure

\footnotetext{
* Corresponding author: jinwoo.kim@epfl.ch
} 
of the step. Sufficient time, usually a few weeks, was allowed until equilibrium between the sample and the surrounding air is reached.

Table 1: List of the saturated saline solutions. RH and $\psi$ values are at a reference temperature of $25^{\circ} \mathrm{C}$.

\begin{tabular}{|c|c|c|}
\hline $\begin{array}{c}\text { Solutions } \\
\text { (salts) }\end{array}$ & $\begin{array}{c}\mathrm{RH} \\
{[\%]}\end{array}$ & $\begin{array}{c}\psi \\
{[\mathrm{MPa}]}\end{array}$ \\
\hline $\mathrm{K}_{2} \mathrm{SO}_{4}$ & 97 & 4 \\
\hline $\mathrm{KCl}$ & 85 & 24 \\
\hline $\mathrm{Mg}\left(\mathrm{NO}_{3}\right)_{2}$ & 55 & 87 \\
\hline $\mathrm{LiI}$ & 18 & 216 \\
\hline $\mathrm{LiBr}$ & 8 & 351 \\
\hline
\end{tabular}

The water retention behavior and strains are shown in Figure 2 for the case of a desiccation-imbibitiondesiccation scenario. The water content variation (Figure 2a) clearly shows water loss upon desiccation and uptake upon imbibition, with noticeable hysteresis in the low suction range. The axial strain (Figure $2 b$ ) shows that significant swelling occurred upon imbibition and also suggests that much of this strain was irreversible, whereas the radial strain (Figure 2c) was found to be relatively small and generally reversible. The relative magnitude in the axial and radial strains and the irreversible strain concentrated in one direction indicate significant anisotropy with respect to the bedding plane orientation.

\section{References}

1. Ewy, R. T. (2015). "Shale/claystone response to air and liquid exposure, and implications for handling, sampling and testing." Int. J. Rock Mech. Min. Sci. 80, pp. 388-401.

2. Ferrari, A., Minardi, A., Ewy, R., and Laloui, L. (2018). "Gas shales testing in controlled partially saturated conditions." Int. J. Rock Mech. Min. Sci. 107, pp. 110-119.

3. Fredlund, D. G., and Rahardjo, H. (1993). Soil mechanics for unsaturated soils. Wiley, New York, NY.

4. Kim, J., Ferrari, A., Ewy, R., \& Laloui, L. (2021). "Gas shale swelling and shrinkage characterized by controlled suction experiments." Poster presented at InterPore2021. May 31-Jun. 4. Online.

5. Minardi, A., Ferrari, A., Ewy, R., and Laloui, L. (2018). "The impact of the volumetric swelling behavior on the water uptake of gas shale." J. Nat. Gas Sci. Eng. 49, pp. 132-144.

6. Romero, E. (2001). "Controlled suction techniques." Proc. $4^{\circ}$ Simpósio Brasileiro de Solos Nâo Saturados. 2001. Porto Alegre, Brazil. pp. 535-542.

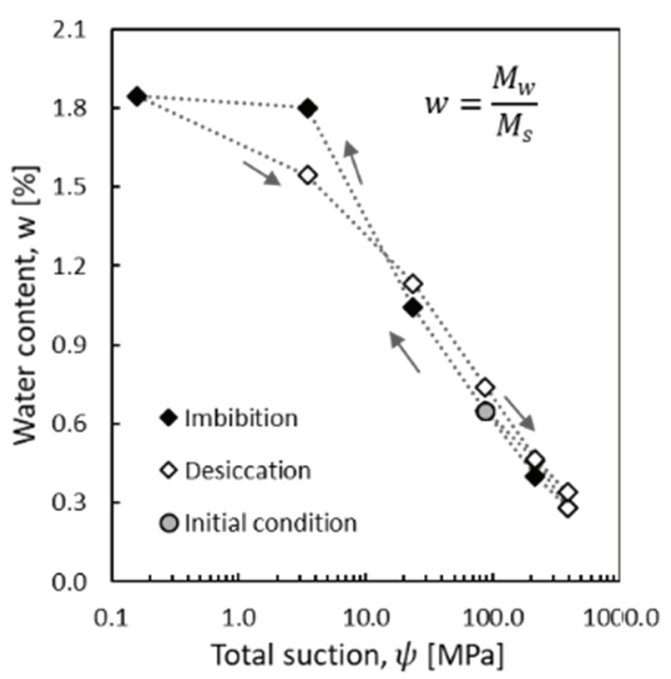

(a)

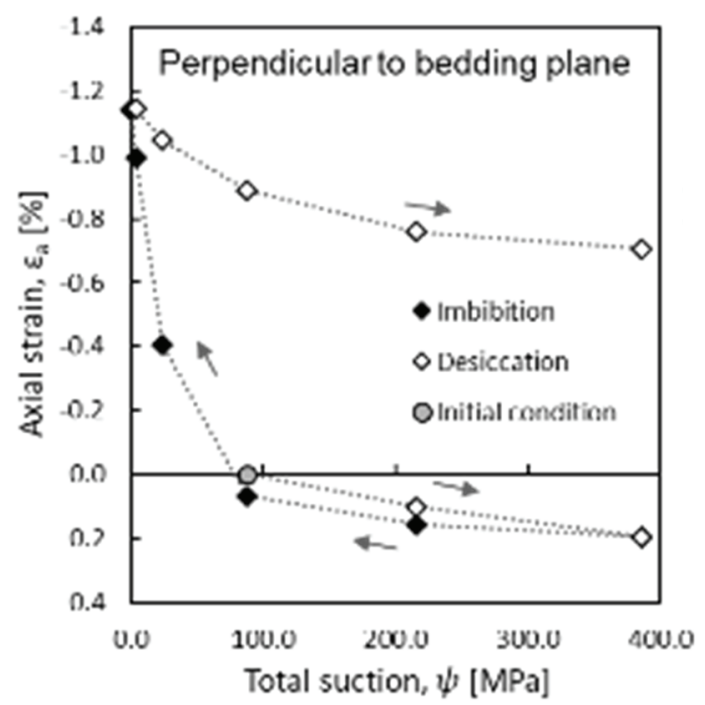

(b)

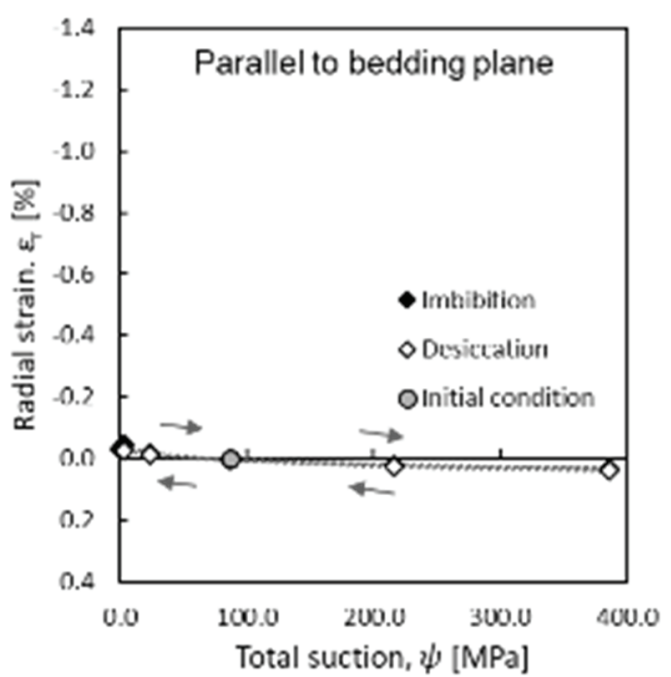

(c)

Fig. 2: Observed sample responses: a) water content, b) axial strain, and c) radial strain 